\title{
BLOOD PRESSURE CHANGES IN NORMALS AND IN HYPERTENSIVES AFTER INTRAVENOUS EPINEPHRINE AND HISTAMINE
}

\author{
By WAYNE GORDON AND GEORGE LEVITT \\ (From the Lasker Foundation for Medical Research and the Department of \\ Medicine, the University of Chicago, Chicago)
}

(Received for publication January 28, 1935)

The conception that peripheral vascular irritability may be an important factor in the mechanism of production of hypertension has led to a search for vascular or vasomotor stimuli that would further knowledge both of the physiology of hypertension and of the state of individual patients from time to time. Large numbers of agents, both physical and chemical, have been tried. Of the various chemical stimuli for testing peripheral vasomotor irritability in hypertensive disease, epinephrine has been frequently chosen. In spite of this, there has been lack of agreement concerning the nature of the reactions in hypertension. Jensen (1) reviewed literature and carried out experiments with subcutaneous epinephrine. He found that repetition of tests regularly produced a sharp pressor response, and that the response to the first test was the chief variable. In the normal there was usually a slow systolic rise; in the hypertensives some had little response and others a very strong response on the first test.

About ten years ago a considerable amount of work, reported chiefly in the German literature, was done with injection of epinephrine intravenously. Csépai, Fornet and Toth (2), and Hetényi and Sümegi (3) reported frequent but not constant increased sensitivity to epinephrine in hypertension as judged by the absolute increase in blood pressure following standard doses of epinephrine hydrochloride, usually $0.01 \mathrm{mgm}$. Jansen (4), using doses of from 0.005 to 0.02 mgm., reported diminished sensitivity in about half the hypertensives, as judged by the amount of elevation of systolic pressure expressed as a percentage of the base systolic pressure. All these investigators observed depressor responses at times in hypertension. Deicke and Hülse (5) judged the type of response rather than its magnitude; in a small series they observed a depressor response in the normal, diphasic response in ne- phritis and in hypertension with severe kidney damage, and no change in blood pressure in uncomplicated essential hypertension following injections of $0.005 \mathrm{mgm}$. They regarded pressor response to this dose as indicative of heightened sensitivity to epinephrine and believed it characteristic of patients with renal damage. Hess (6) chose as a criterion the minimal active dose of epinephrine, which gave as a rule negative or diphasic blood pressure curves; she reports lower minimal doses in hypertension, although there was considerable overlap into the normal minimal dose range. She considered as normal sensitivity 0.000005 to $0.000010 \mathrm{mgm}$. per $\mathrm{kgm}$. body weight for the minimal active dose; in a $60 \mathrm{kgm}$. subject this would mean doses of 0.0003 to $0.0006 \mathrm{mgm}$. Her sensitive individuals reacted at times to doses as low as $0.0000025 \mathrm{mgm}$. per $\mathrm{kgm}$. Szondi (7) also pointed out the difficulty in drawing conclusions from the direction of the blood pressure change following the injection of a single dose of epinephrine, and observed that in most subjects a depressor response was obtained if the dose was made low enough. He agreed with Hess in the use of minimal depressor doses as a measure of sensitivity to epinephrine.

The various criteria for judging blood pressure reactions to intravenous epinephrine may be summed up under the following heads: (1) type of response; (2) size of dose required to produce any effect or to produce stated effects; and (3) magnitude of response.

We have carried out 102 experiments on 63 subjects in which we have attempted to observe the response to intravenous epinephrine hydrochloride from all three standpoints. Histamine dihydrochloride also was administered in $86 \mathrm{ex}-$ periments in the same fashion. Of the 63 subjects 25 had primary hypertension, 9 had glomerulonephritis, 16 were normal, 7 had normal blood pressures at the time of the examinations but 
were known to have hypertension at times, 3 had arteriosclerosis, and 3 had hyperthyroidism.

\section{METHOD}

The subject lay at ease on a couch, and a needle connected with a syringe containing salt solution was inserted into a vein in the antecubital fossa. The blood pressure was observed every 30 seconds in the opposite arm by the auscultatory method, throughout the experiment. When the blood pressure had reached a constant level, usually after 15 to 25 minutes, a measured dose of epinephrine hydrochloride in saline solution was injected at such a speed as to require as nearly as possible 30 seconds for the injection. A base line was generally reached again after 4 to 8 minutes so that another dose could be administered through the same needle. The epinephrine solutions were freshly prepared either from solid tablets or from $1: 1000$ solution in dilutions of $1: 10,000$ to $1: 1$,000,000 . It was ascertained on three subjects that the reactions were the same whether the tablet or the commercial solution were the source of the epinephrine. The doses regularly used were $0.0010,0.0015,0.0025,0.0040,0.0060$, 0.0100 , and $0.0150 \mathrm{mgm}$.; larger and smaller doses were used when necessary to determine minimal and maximal depressor doses. The order in which various doses were given was varied in some experiments; it did not appear to affect the results. We found it convenient, as a rule, to work from small to large doses, because of psychic stimulation from palpitation after the larger doses. The histamine was used at times before and at times after epinephrine. It was prepared from 1:1000 solution of the dihydrochloride in the same dilutions as epinephrine.

\section{RESULTS}

In evaluating the blood pressure results some arbitrary standards were set up for the sake of uniformity. Changes of $2 \mathrm{~mm}$. were regularly disregarded. Changes of $4 \mathrm{~mm}$. were counted if they were confirmed by repetition or if a slightly greater dose produced a slightly greater change in the same direction, provided the base line were satisfactory. Changes of $4 \mathrm{~mm}$. were also counted as significant when they represented the short arm of a diphasic response. Otherwise changes of $6 \mathrm{~mm}$. or more only were held to be significant.

Type of response. The type of reaction followed the same general pattern in all groups. With few exceptions the least effective dose produced a fall in both systolic and diastolic pressures. As the dose was increased a pressor phase appeared following the depressor phase. With further increase in dosage the depressor phase grew less in magnitude until it was no longer found, while the pressor reaction increased. Depressor reactions were found at some dosage in 89 of 102 experiments. They were transitory and occurred 30 seconds after the cessation of injection. Usually the pressure was at the base line or higher at the end of another 30 seconds. The pressor phase began 30 to 60 seconds after the cessation of injection, sooner with large than with medium doses. It was usually at its highest 60 or 90 seconds after the injection, and the base line was reached in 1 to 5 , usually about $2 \frac{1}{2}$, minutes. The diastolic pressure generally followed the direction of the systolic, except that where a pressor response was obtained the diastolic usually rose and fell about 30 seconds before the systolic. This was true even when the systolic rise was preceded by a fall.

The 13 experiments in which depressor response was not found were distributed as follows : primary hypertension, 7 of 41 experiments ; nephritis, 5 of 26 ; transitory hypertension, 1 of 8 ; normals and others, none of 27 . It is possible that depressor reactions were present at times and not observed because of their transitory character.

Size of dose. The dosage level at which the various phases of the response were obtained varied within wide limits. Figure 1 gives frequency curves for two groups, those in whom the base systolic pressure is below $150 \mathrm{~mm}$., and those in whom it is $150 \mathrm{~mm}$. or more. The minimal effective dose was found at 0.0010 or less, 0.0015 , and $0.0025 \mathrm{mgm}$. with practically equal frequency; in 15 experiments it exceeded those figures. The hypertensive group included a slightly greater spread at each end, but presented no significant difference in general trend. The spread is still more apparent in the curve for minimal depressor doses, as 11 of the 13 experiments in which the minimal dose was pressor were among the hypertensive group. There was no significant 
difference between the minimal pressor doses of the two groups. In the curves of maximal doses at which depressor response was observed, there is a mode at $0.0040 \mathrm{mgm}$. in the lower and a mode at 0.0025 in the higher pressure group. The latter group, however, contains also more experiments in which the maximal depressor doses were unusually high, and these tend to counterbalance the difference in modes. depressor doses did not appear to vary significantly from group to group. The distribution of the dosages in the transitory hypertension experiments appears to be well within the normal range for each of the effects.

There was a considerable degree of variation in the responses of a single individual on different days for no demonstrable reason. In one subject, a man suffering from acute glomeruloneph-

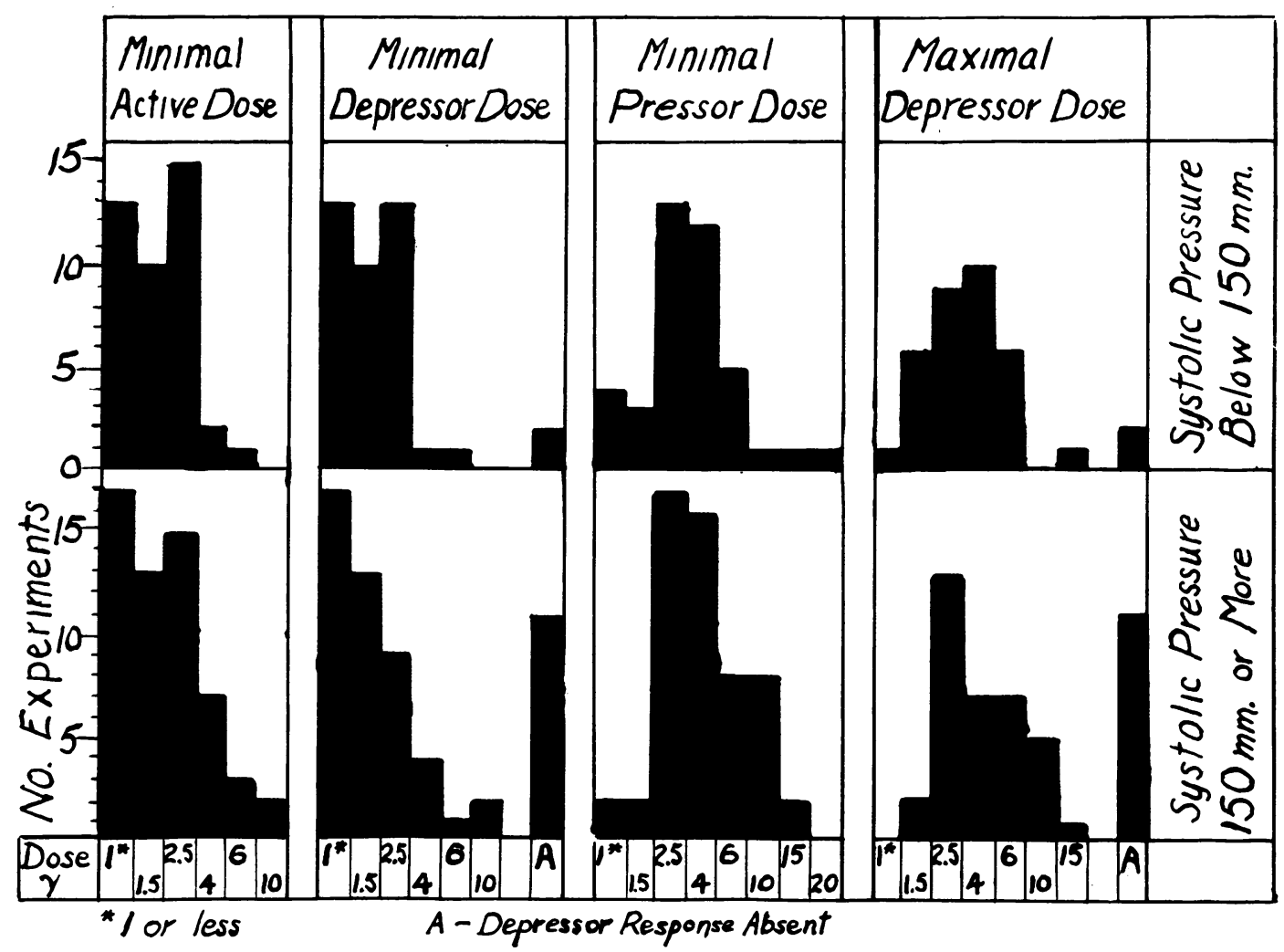

Fig. 1. Frequency with Which Minimal Active, Minimai. Depressor, Minimal Pressor, ani Maximal Depressor Doses of Epinephrine Hyinochlorine Were founi at Various Levels in Subjects Classified According to Systolic Pressure.

Similar frequency curves for the diagnostic classifications are shown in Figure 2. The minimal activity dose was found more frequently in primary hypertension at lower, and in nephritis at higher, levels than in the normal. In some subjects with primary hypertension, however, there were also very large minimal doses. The minimal depressor doses varied in the same way as minimal active doses. The minimal pressor doses tended to be slightly higher in primary hypertension than in the other groups. The maximal ritis with subsiding hypertension, there was a distinct tendency for depressor responses to be more pronounced when the systolic pressure was higher, but in no other subject was this relation seen.

Magnitude of response. When blood pressures are observed at intervals, rather than continuously, any conclusions with regard to magnitude of change depend on the assumption that the peaks of the blood pressure curves are as likely to be observed in one subject as in another, since it is 


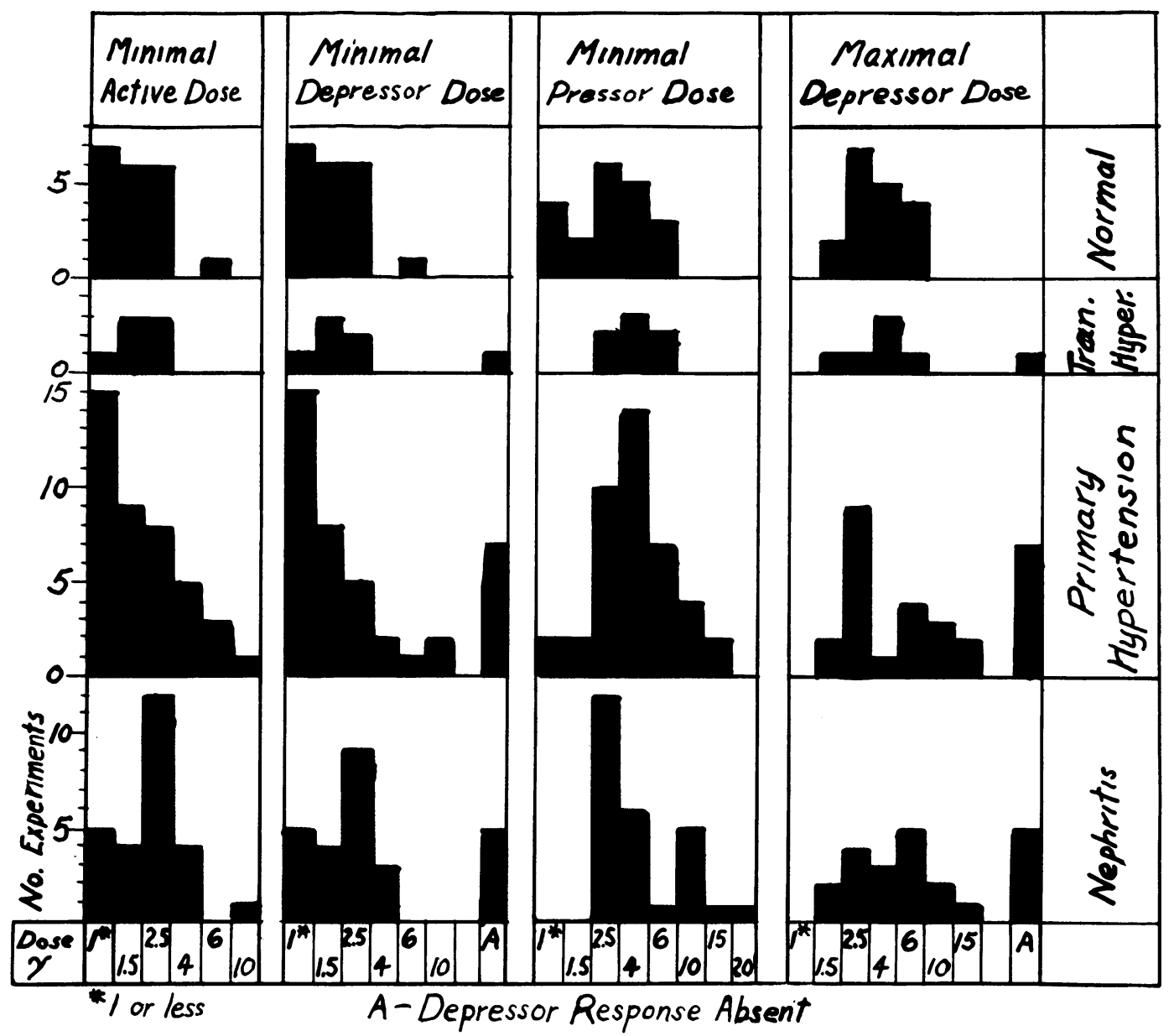

Figi. 2. Frequency with Which Minimal Active, Minimal Depressor, Minimal Pressor. and Maximal Depressor Doses of Epinephrine Hytrochlorile. Were folvid at Various Levels in Subjects Classifieid According to Diagnosis.

Tran. Hyper. refers to transitory hypertension.

TABLE

Magnitude of changes in systolic pressure observed after intravenous administration of epinephrine hydrochloride

\begin{tabular}{|c|c|c|c|c|c|c|c|c|c|}
\hline Dose & $\begin{array}{l}\text { Initial } \\
\text { systolic } \\
\text { pressure }\end{array}$ & $\begin{array}{l}\text { Frequency } \\
\text { of falling } \\
\text { pressure }\end{array}$ & $\begin{array}{l}\text { Mean initial } \\
\text { systolic } \\
\text { pressure }\end{array}$ & Mean fall & Mean fall & $\begin{array}{l}\text { Frequency } \\
\text { of rising } \\
\text { pressure }\end{array}$ & $\begin{array}{l}\text { Mean initial } \\
\text { systolic } \\
\text { pressure }\end{array}$ & Mean rise & Mean rise \\
\hline$m g m$. & $m m . H g$ & experiments & $m m . H g$ & $m m . H g$ & per cent & experiments & $m m . H g$ & $m m . H g$ & per cent \\
\hline 0.0015 & $\begin{array}{l}100-139 \\
140-179 \\
180-230\end{array}$ & $\begin{array}{l}21 \\
15 \\
17\end{array}$ & $\begin{array}{l}123 \\
160 \\
205\end{array}$ & $\begin{array}{r}6.9 \\
8.3 \\
14.6\end{array}$ & $\begin{array}{l}5.6 \\
5.2 \\
7.1\end{array}$ & $\begin{array}{l}6 \\
3 \\
7\end{array}$ & $\begin{array}{l}128 \\
151 \\
203\end{array}$ & $\begin{array}{l}7.0 \\
6.7 \\
9.7\end{array}$ & $\begin{array}{l}5.5 \\
4.4 \\
4.8\end{array}$ \\
\hline 0.0025 & $\begin{array}{l}100-139 \\
140-179 \\
180-230\end{array}$ & $\begin{array}{l}25 \\
18 \\
21\end{array}$ & $\begin{array}{l}123 \\
156 \\
201\end{array}$ & $\begin{array}{r}7.7 \\
8.6 \\
10.2\end{array}$ & $\begin{array}{l}6.3 \\
5.5 \\
5.1\end{array}$ & $\begin{array}{l}17 \\
16 \\
17\end{array}$ & $\begin{array}{l}124 \\
157 \\
201\end{array}$ & $\begin{array}{l}5.9 \\
6.8 \\
9.0\end{array}$ & $\begin{array}{l}4.8 \\
4.3 \\
4.5\end{array}$ \\
\hline 0.0040 & $\begin{array}{l}100-139 \\
140-179 \\
180-230\end{array}$ & $\begin{array}{l}17 \\
18 \\
16\end{array}$ & $\begin{array}{l}120 \\
159 \\
206\end{array}$ & $\begin{array}{r}9.4 \\
9.3 \\
13.0\end{array}$ & $\begin{array}{l}7.7 \\
5.9 \\
6.3\end{array}$ & $\begin{array}{l}26 \\
18 \\
22\end{array}$ & $\begin{array}{l}123 \\
159 \\
200\end{array}$ & $\begin{array}{r}7.2 \\
7.3 \\
11.7\end{array}$ & $\begin{array}{l}5.9 \\
4.6 \\
5.9\end{array}$ \\
\hline
\end{tabular}


obvious that they cannot be observed consistently. In spite of this qualification it is possible to judge the magnitude of response in a general way.

The series of responses to each single dose was divided into three groups according to base-line systolic pressure, the divisions being made at 140 and $180 \mathrm{~mm}$. The averages of all pressor responses and of all depressor responses within these groups were compared both in absolute magnitude and as fractions of the mean systolic pressures within the groups. The figures indicated in Table I for $0.0015,0.0025$, and $0.0040 \mathrm{mgm}$. are typical. It will be seen that while the average rise or fall is greater from the higher base line, its magnitude, expressed as a percentage of systolic pressure, is practically the same in hypertensives as in those with normal blood pressure.

Histamine. When a sufficient dose of histamine dihydrochloride was given the systolic and diastolic pressures fell. Frequently a sharp fall was followed by a transient rebound to 4 or $6 \mathrm{~mm}$. above the previous base line. The depressor response, when present, was found 30 seconds after the cessation of the injection, and had disappeared in another 30 seconds. It was regularly accompanied by a flush: doses just insufficient to cause demonstrable fall in blood pressure were also, as a rule, productive of flushing.

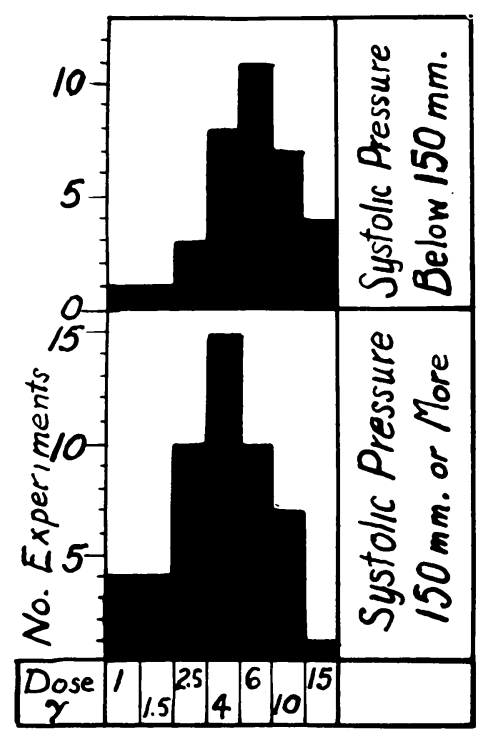

Fig. 3. Frequency with Which the Minimal Depressor Dose of Histamine Dihydrochloride Was Found at lakious Levels in Subjects Classified ACcording to Systolic Pressure.
The least dose at which significant depression of the systolic pressure was observed varied from $0.0010 \mathrm{mgm}$. to $0.0150 \mathrm{mgm}$. The frequency with which the subjects reacted to the various closes is indicated in Figure 3. It is evident that on the average histamine produces a fall in blood pressure at slightly smaller dosage when the blood pressure is high than when it is low. The overlap between the hypertensive and non-hypertensive minimal dose ranges is extensive.

Scatter graphs, in which the minimal depressor close of epinephrine was plotted against the minimal depressor dose of histamine for the same subject at the same sitting, showed no apparent relationship. We have not attempted to form any conclusions from the magnitude of response to histamine because of the extreme rapidity of the changes and the marked variation of the magnitude of change on even immediate repetition.

\section{DISCLSSION}

The differences that we have noted between hypertensive and normal individuals in their response to epinephrine and to histamine have in no case been striking. For both substances the type of response is the same in the one group as in the other. The doses at which various responses to epinephrine were obtained show only slight differences. A slightly more definite difference as regard usual size of dose was observed in the histamine experiments, but there was no clear-cut separation of groups on the basis of close required. Differences in magnitude of response appear to be insignificant. It is thus evident that neither epinephrine nor histamine, in the way we have used them, is the ideal vasomotor stimulus for the study of hypertensive and "prehypertensive" states.

The observed similarity admits of several interpretations. It is possible that the effects of both are so complicated by cardiac, peripheral vascular. pulmonic vascular, and nervous factors as to make the blood pressure changes they produced valueless as measures either of vasomotor irritability or of vascular tonus. It may be that the method is too gross to detect small differences in irritability or tonus. Furthermore, it is possible that the mechanism of blood pressure changes after such stimulation is different from the mechanism of blood pressure regulation under ordinary condi- 
tions. Finally, it is possible that the vasomotor irritability is actually measured in a rough way, but that the irritability of the hypertensive individual is essentially the same as that of the normal. Lacking adequate evidence as to the mechanism of the blood pressure changes, particularly of the depressor responses to epinephrine, we have not attempted to decide the cause of the major resemblances and minor differences in the reactions of normals and of hypertensives.

\section{SUM MARY}

The blood pressure changes were observed in normal and in hypertensive subjects following the intravenous injection of varying doses of epinephrine and of histamine. Hypertensive subjects reacted to these substances in the same general way as did those with normal blood pressure. With minor variations the doses of epinephrine required to produce effects in the normals were about the same as those required to produce the same effects in hypertensives. The blood pressure changes after epinephrine injection were approximately equal when expressed as a percentage of systolic pressure. Hypertensives reacted on the whole to slightly smaller doses of histamine than normals.

\section{BIBLIOGRAPHY}

1. Jensen, J., The adrenalin test in hypertension. Am. Heart J., 1930, 5, 763.

2. Csépai, K., Fornet, B., and Toth, K., Über die klinische Bedeutung der Bestimmung der Adrenalinempfindlichkeit. Wien Arch. f. inn. Med., 1923, 6, 383.

3. Hetényi, S., and Sümegi, S., Über die wirkliche Adrenalinempfindlichkeit der Hypertoniker. Klin. Wchnschr., 1924, 3, 188.

Die Adrenalinblutdruckkurven der essentiellen $\mathrm{Hy}$ pertoniker. Klin. Wchnschr., 1925, 4, 2298.

4. Jansen, W. H., Blutdruckstudien. III. Adrenalinversuche bei normalen Blutdruck und arteriellem Hochdruck. Deutsches Arch. f. klin. Med., 1925, 147, 339.

5. Deicke, E., and Hülse, W., Adrenalinversuche bei Hypertonien. Deutsches Arch. f. klin. Med., 1924, 145, 360 .

6. Hess, O., Neue Untersuchungen über die Adrenalinempfindlichkeit beim Menschen. Verhandl. d. deutsch. Geselisch. f. inn. Med., 1924, 36, 262.

7. Szondi, L., Beiträge zur Klinik und Theorie der Negativen oder paradoxen Adrenalinempfindlichkeit. Klin. Wchnschr., 1925, 4, 1349. 